\title{
Study of Injection Molding Process Simulation and Mold Design of Automotive Back Door Panel
}

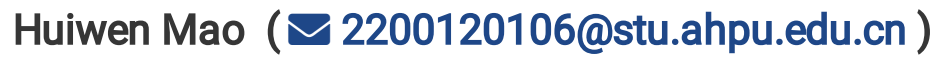

Anhui Polytechnical University

Youmin Wang

Anhui Polytechnic University

Deyu Yang

Anhui Polytechnic University

\section{Research Article}

Keywords: plastic back door, ANSYS, injection molding simulation, mold design, finite element analysis

Posted Date: June 7th, 2021

DOl: https://doi.org/10.21203/rs.3.rs-524782/v1

License: (1) This work is licensed under a Creative Commons Attribution 4.0 International License. Read Full License 


\title{
Study of Injection Molding Process Simulation and Mold Design of Automotive Back Door Panel
}

\author{
Huiwen Mao, Youmin Wang, and Deyu Yang
}

School of Mechanical and Automotive Engineering, Anhui Polytechnic University, Wuhu, Anhui, 241000, China

Correspondence should be addressed to Huiwen Mao; 2200120106@stu.ahpu.edu.cn

\begin{abstract}
Numerical simulation of the injection molding process of the outer panel of the automotive plastic rear door and mold design is presented here. CATIA is used to design the original automotive steel structure. In order to efficiently design the panels; finite element analysis is used to verify whether the designed parts meet the mechanical properties requirements such as light weight, low fuel consumption, short production cycle, strong modeling design, high corrosion resistance and good recovery. To simulate the injection molding process, CAE software such as ANSYS and HYPERWORKS are used to analyze the back door of the selected material. After the numerical analysis, suitable material is selected, so that the modal and thermodynamic properties of the product could be satisfied as well as improved. In this paper, UG is used to design the convex and concave mold for the injection molding of the automobile's plastic back door panel. Combined with the characteristics of the parts and the design requirements of the injection mold, the multi-scheme design of the pouring and cooling system is carried out. By comparing the effects of different gating and cooling systems on injection molding, the best gating and cooling system is selected.
\end{abstract}

Keywords: plastic back door; ANSYS; injection molding simulation; mold design; finite element analysis.

Declarations: I confirm I have provided a complete 'Declarations' section in my manuscript.

Funding:This work was supported by the University Synergy Innovation Program of Anhui Province (GXXT-2019-004), the Teaching Research Project of Anhui Educatio 
n Department (2019jyxm0229), and the Natural Science Foundation of Anhui Provinc e Education Department (KJ2017ZD12).

Conflicts of interest/Competing interests: We have no potential conflict of interest. Availability of data and material: The date used to support the fingings of this study are included within the article.

Code availability: Some or all data, models, or code generated or used during the study are available from the corresponding author by request.

Authors' contributions: In this paper, numerical FEM analysis of the plastic rear door outer panel of a certain car is performed. ANSYS and modal analysis software is used to verify whether the designed part can meet its mechanical performance requirements and related mold design issues. According to the structure, material, applications and mechanical properties of the parts, the model HTF300J / TJ of the injection molding machine is selected.

Ethics approval: Ethics approval was not required for this research.

Consent to participate: Yes, my co-authors and I agree with the participate.

Consent for publication: Yes, my co-authors and I agree with the publication.

\section{Introduction:}

With tremendous development of the automobile industry, the energy problem in today's society has become increasingly prominent; which has further resulted in higher public demands of lightweight and low energy consuming automobiles ${ }^{[1]}$. From literature ${ }^{[2 \sim 4]}$, it is found that substituting plastic for steel can not only reduce the design and manufacturing costs, but also the weight of the vehicle parts.

The mold market is developing rapidly with stable growth in manufacturing of plastic products where injection molds are used as the main supporting process equipment. At present, more than $90 \%$ of my country's automotive interior and exterior decorative plastic parts are produced by designated plastic molds ${ }^{[6]}$. In short, the production process is to melt the plastic material by heating to turn it into a high-temperature liquid, and use different methods to send it into the mold, and finally make it into a finished product through the stages of holding pressure and 
cooling.

There is still a big gap between my country's lightweight level and foreign countries. At present, high-strength steel is still used most widely and the lightweight scheme of replacing steel with plastic has not been widely used. The lightweight solution is currently in the promotion and research stage. Judging from the current situation, the choice of multiple materials will be a major trend in the future ${ }^{[8]}$.

This paper uses CATIA to create the three-dimensional model of the outer panel of the automobile all-plastic rear door, and then uses CAE to analyze its structure. In view of the particularity of the outer panel of the plastic back door, different materials are tried and compared it with the best material type. The mold is designed according to the design criteria of the injection mold. Based on the results simulated by Moldflow, the pouring and cooling systems of the injection mold will be studied separately.

\section{Design of the outer panel structure of the automobile all-plastic rear door}

The main content of the structural design of the outer panel of the all-plastic back door is the selection of materials, the design of the wall thickness of the parts, and the analysis of the mechanical properties of the parts.

1.1. Automobile All-Plastic Back Door Outer Panel Material. The inner panel of the back door mainly plays the role of a bearing; providing strength and stiffness, while the outer panel of the back door mainly realizes the appearance modeling, so that there are great differences found between them during the selection of materials and design analysis stage. The material of choice for automotive plastic rear doors is modified PP, which has the advantages of high specific strength, recyclability, and low cost. The commonly used modified PP materials include pp-gf-30 / 40 / 50, pp-lgf-30 / 40 / 50, pp-epdm-20 / 30, etc. The main performance indexes are shown in Table 1.

TABLE 1: Performance indexes of thermoplastics.

\begin{tabular}{ccccc}
\hline Glass fiber & Tensile strength & Flexural & Impact strength & Density \\
$(\%)$ & $(\mathrm{MPa})$ & Strength $(\mathrm{MPa})$ & $\left(\mathrm{KJ} / \mathrm{m}^{3}\right)$ & $\left(\mathrm{g} / \mathrm{cm}^{3}\right)$ \\
\hline
\end{tabular}


While selecting materials for the inner and outer panels of the plastic rear door, it should be taken into consideration that the inner panel is mainly used for mechanical load-bearing and the outer panel is mainly for aesthetics. Because the elastic modulus of PP-LGF-30 material is $6502.3 .3 \mathrm{MPa}$, the shear modulus is $1482.5 \mathrm{MPa}$, the maximum shear stress is $0.25 \mathrm{MPa}$, and the elastic modulus of PP-EPDM-T30 material is $2005.3 \mathrm{MPa}$, the shear modulus is $600 \mathrm{MPa}$, the maximum shear stress is $0.25 \mathrm{MPa}$. Comparing the parameters of the two materials and considering the working conditions of the inner and outer panels in actual applications, PP-LGF-30 was finally selected as the material for the inner panel and PP-EPDM-T30 as the material for the outer panel.

1.2. The wall thickness design of the outer panel of the automobile plastic back door. When considering mechanical properties such as the strength, modal and thermal deformation of the outer panel of the plastic back door, the thickness of the plastic part should be controlled within a reasonable range. Therefore, when selecting the material thickness in this article, the calculation is strictly carried out according to the formula for calculating the thickness of the plastic part. The outer panel of the automobile plastic rear door studied in this paper is based on the rear door of a domestically-produced vehicle. The structure is shown in Figure 1.

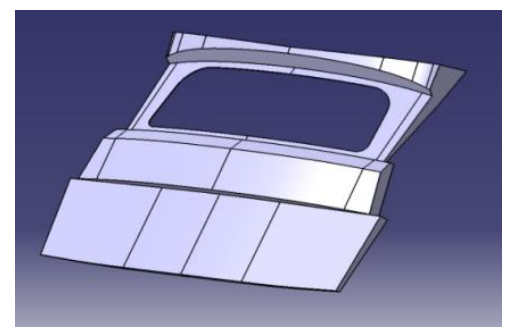

FIGURE 1: Automotive plastic back door panel.

The material thickness is:

$$
S=A / B \times S^{*} \times(0.8 \sim 0.95),
$$

where $S$ is the original thickness, $B$ is projected area, $S^{*}$ is average thickness, $A$ is surface area.

This article uses three-dimensional software to analyze the plastic back door in 
Figure 1 and finds that the product surface area $\mathrm{A}$ is $1024000 \mathrm{~mm}^{2}$, and the product projection area B is $980000 \mathrm{~mm}^{2}$. The thickness of the modified PP material of automobile parts is usually $1.5 \mathrm{~mm}-3 \mathrm{~mm}$. Considering the mechanical performance requirements and related design standards of the designed products, $\mathrm{S}^{*}$ in this paper is $3 \mathrm{~mm}$. Considering the actual processing situation, the result obtained by the above formula should be multiplied by 0.8-0.95. After calculating using formula (1), the thickness of the plastic part can be obtained in this article.

$$
S=1024000 / 980000 \times 3 \times 0.8 \approx 2.5 \mathrm{~mm}
$$

Although the plastic back door satisfies the principle of plastic part thickness design, it cannot be well guaranteed whether it can meet the same mechanical performance requirements as the original steel back door. Therefore, this paper also combines an equal strength design criterion in the design process. The elastic modulus and moment of inertia of plastic and steel parts should meet the following condition.

$$
(E I)_{\text {novel material }}=(E I)_{\text {Sheet metal material }},
$$

where $E$ is modulus of elasticity of material and $I$ is moment of inertia.

Considering the connection and use of the inner and outer panels of the back door, the inner and outer panels are designed as parts of equal thickness. This paper uses the principle of equal strength design of the inner plate to check whether the thickness of the designed outer plate is reasonable. According to the design guidelines and related regulations of the automobile industry, the thickness of the sheet metal parts of the automobile four-door and two-cover is generally about $0.8 \mathrm{~mm}$, the elastic modulus of the inner plate material is about $6202.3 \mathrm{MPa}$, and the modulus of elasticity of steel is $206 \mathrm{GPa}$. From the above formula, the thickness of the replacement material is found as

$$
h=H \sqrt[3]{\frac{E_{\text {sheet mentai parts }}}{E_{\text {PP composit materal }}}}=0.8 \times \sqrt[3]{\frac{20600}{6502.3}} \approx 2.5 \mathrm{~mm}
$$

where $h$ is thickness of back door inner panel and $H$ is thickness of original sheet metal parts.

Through formulas (1) and (2), it can be seen that the thickness of the inner and 
outer panels of the back door is within the error range. Therefore, the thickness of the outer panel of the plastic back door is set at $2.5 \mathrm{~mm}$. The three-dimensional model of the outer panel of the plastic back door is shown in Figure 2 below. The plastic back door not only meets the principle of plastic thickness design, but can also achieve the same mechanical properties as the original steel back door.

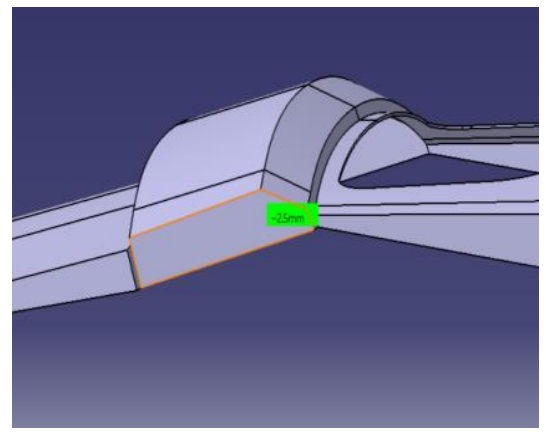

FIGURE 2: Back door plate

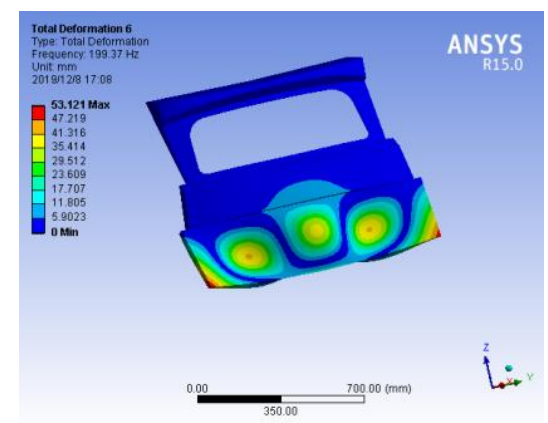

FIGURE3: Six - order modal cloud image of plastic back door.

\subsection{Finite Element Analysis of the Outer Panel of Automobile Plastic Rear Door.}

Through modal analysis, the resonance and noise of automobile parts in use can be reduced to a minimum. Since there are countless patterns in component analysis, this article only considers the first six sequences of pattern analysis. When using HyperWorks and ANSYS to analyze the mechanical properties of plastic backdoor, this paper firstly divides the backdoor mesh. On the basis of mesh division, this paper uses ANSYS Workbench to conduct modal analysis on the plastic rear door panel. The sixth mode of plastic back door plate is shown in Fig. 3.

By analyzing the modal cloud diagram, the modal frequencies of the first six orders of the plastic back door are obtained along with the magnitude of the deformation of the plastic back door at the resonance condition - i.e. when the frequency of each order of the back door is the same as the frequency of the external 
excitation. After comparing the modes of plastic and steel back doors, this paper draws the six-order front modals of the original steel back door and the front six-order modalities of the plastic back door into Table 2.

$\mathrm{T}_{\mathrm{ABLE}} 2$ : Modal comparison.

\begin{tabular}{ccccc}
\hline Order & $\begin{array}{c}\text { Plastic back-up door } \\
\text { model }(\mathrm{Hz})\end{array}$ & $\begin{array}{c}\text { Steel rear door } \\
\text { model }(\mathrm{Hz})\end{array}$ & $\begin{array}{c}\text { Difference } \\
(\mathrm{Hz})\end{array}$ & $\begin{array}{c}\text { Percentage } \\
\text { difference }(\%)\end{array}$ \\
\hline 1 & 45.181 & 42.736 & 2.445 & 5.72 \\
2 & 55.463 & 53.924 & 1.539 & 2.85 \\
3 & 101.55 & 100.63 & 0.92 & 0.914 \\
4 & 149.53 & 148.4 & 1.13 & 0.761 \\
5 & 159.92 & 158.04 & 1.88 & 1.19 \\
6 & 199.37 & 197.22 & 2.15 & 1.09 \\
\hline
\end{tabular}

Compared to the modes of plastic and steel back doors, the first-order modal value of plastic parts is $5.72 \%$ higher than that of steel, and the second-order modal value of plastic parts is $2.85 \%$ higher than that of steel. The modal values of the first two orders have increased greatly, and the modal values of the last four orders of plastic parts have also increased compared with those made of steel, with an increase of $0.914 \%, 0.761 \%, 1.19 \%$, and $1.09 \%$ respectively. Therefore, the first six modes of the plastic rear door outer panel all meet the modal requirements of the original steel rear door outer panel. At the same time, the low-order mode of the outer panel of the plastic back door has a greater increase than the high-order mode, and the low-order mode of the object has a higher degree of influence on the vibration amplitude than the high-order mode. Therefore, the PP composite material meets the design requirements.

\subsection{Analysis of Thermal Deformation of Outer Panel of Automotive Plastic Rear}

Door. In the automotive industry, the natural weather temperature and the possible temperature in the actual application process should be taken into consideration. Therefore, the thermal analysis temperature of the plastic back door was set at $-23^{\circ} \mathrm{C}$ $\sim 23^{\circ} \mathrm{C}$ and $23^{\circ} \mathrm{C} \sim 80^{\circ} \mathrm{C}$, respectively. First, this paper carried out the pre-processing of 
the finite element analysis of the designed back door structure, and then carried out the simulation analysis after the completion of the processing operation. The analysis results are shown in Figure 4 and Figure 5.

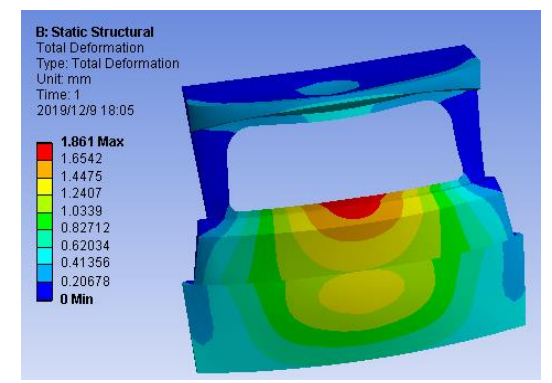

FIGURE 4: Thermal deformation at $23^{\circ} \mathrm{C} \sim 80^{\circ} \mathrm{C}$.

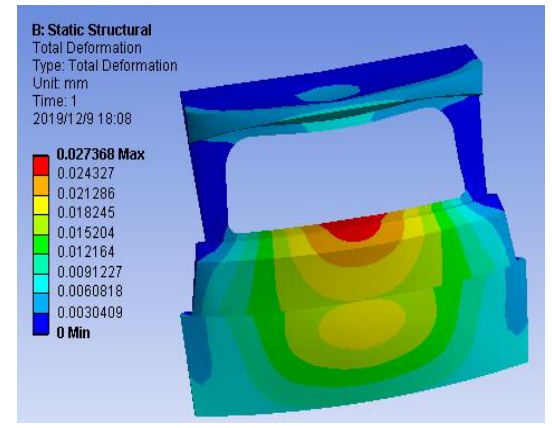

FIGURE 5: Thermal deformation at $23^{\circ} \mathrm{C} \sim-23^{\circ} \mathrm{C}$.

As can be seen from Figure 4, when the temperature changes from $23^{\circ} \mathrm{C}$ to $80^{\circ} \mathrm{C}$, the maximum deformation of the plastic back door plate is at the center of the outer plate. At this time, the deformation of the plastic rear door plate reached $1.861 \mathrm{~mm}$. Figure 5 shows that when the temperature drops from $23^{\circ} \mathrm{C}$ to $-23^{\circ} \mathrm{C}$, the maximum deformation is still in the center of the product. At this time, the deformation of the plastic rear door plate is $0.027368 \mathrm{~mm}$. The standard requirement is that when the working condition one rises from $23^{\circ} \mathrm{C}$ to $80^{\circ} \mathrm{C}$, the clearance surface difference of the plastic back door should be less than $2 \mathrm{~mm}$. When the second working condition drops from $23^{\circ} \mathrm{C}$ to $-23^{\circ} \mathrm{C}$, the gap surface difference should also be less than $2 \mathrm{~mm}$. Obviously, the analysis results of $1.861 \mathrm{~mm}$ and $0.0027368 \mathrm{~mm}$ are less than $2 \mathrm{~mm}$, so the selection of rear door materials and structural design meet all the requirements.

\section{Design of Injection Mould for Outer Panel of Automobile All-plastic Back}

\section{Door}

Injection molding product quality is a direct reflection of injection mold design and is 
a reasonably important index. The main content of the injection mold design of the back door plate is the choice of injection molding machine and the calculation of the core and cavity of the injection mold of the outer plate.

2.1. Selection of Injection Molding Machine. The injection mold and machine tool of the plastic back door plate of the automobile are an inseparable hence the choice of injection molding machine is also very important. Performance parameters of injection molding machine include maximum injection volume, maximum injection pressure, clamping force, nozzle and aperture, etc.

(1) Maximum Injection Volume

The maximum injection volume of the injection machine should be greater than the total injection volume required by the plastic back door plate.

$$
M \leq G_{1},
$$

where $G_{1}$ is actual maximum injection volume, $M$ is the amount of injection required for molding.

$$
M=n \cdot M_{\text {model }}+M_{\text {pouring }}
$$

where $n$ is cavity number, $M_{\text {model }}$ is weight or volume of plastic parts, $M_{\text {pouring }}$ is gating system's weight or volume.

According to the requirements, $\mathrm{G}_{1}$ should be less than $80 \%$ of the maximum injection volume of the injection molding machine.

$$
M \leq 80 \% G,
$$

Admissible range for $M$ is:

$$
20 \% G \leq M \leq 80 \% G,
$$

The total volume of filling is $700 \mathrm{~cm}^{3}$. The total volume of the gating system is $100 \sim 150 \mathrm{~cm}^{3}$. According to Formula (3), the maximum injection volume range is $875 \sim 1500 \mathrm{~cm}^{3}$.

(2) Clamping Force

In this paper, when designing the mold, it is necessary to set the clamping force reasonably so that it is greater than the thrust caused by melt flow. 


$$
T \geq K \cdot F q / 1000
$$

where $T$ is clamping force, $F$ is the total projected area of the outer plate and the gating system on the parting plane, $q$ is pressure in the cavity, $k$ is safety factor.

The cavity pressure is about $25 \sim 50 \%$ of the injection pressure. Generally, the pressure of the die cavity is $200 \sim 300 \mathrm{~kg} / \mathrm{cm}^{2}$. The projection area of the back door plate is $9800 \mathrm{~cm}^{2}$ when calculating the thickness of the parts. Considering the projected area of the gating system, $F$ is $10000 \mathrm{~cm}^{2}$. According to Equation (7), $T$ can be obtained as $2200 \mathrm{t}$.

$$
\mathrm{T} \geq \mathrm{KF} \cdot \mathrm{q} / 1000=1.1 \times 10000 \times 200 / 1000=2200 \mathrm{t}
$$

The clamping force of the selected injection machine should be greater than 2200 tons. Based on the data analysis and the actual situation of the automobile industry, the maximum injection pressure of the injection molding machine is selected as 60 MPa. After consulting the injection molding machine model manual, the Haitian injection molding machine is finally selected. The model of Haitian injection molding machine is HTF300J/TJ.

\subsection{Calculation of Core and Cavity of Injection Mould for Outer Panel of Plastic} Rear Door of Automobile.

(1) The auto plastic back door panel forming shrinkage rate and cavity size manufacturing deviation are averaged. The average value of the size deviation of the plastic back door plate can be obtained as follows:

$$
A_{\mathrm{s}}-\frac{\Delta}{2}=\left(A_{\mathrm{m}}+\frac{\delta_{\mathrm{z}}}{2}+\frac{\delta_{c}}{2}\right)-\left(A_{s}-\frac{\Delta}{2}\right) S,
$$

where $\Delta$ is automotive plastic back door plate tolerance/mm, $S$ is average shrinkage rate of automotive plastic back door panels, $\delta_{c}$ is automobile plastic back door plate injection mold wear $/ \mathrm{mm}, \delta_{z}$ is mold manufacturing tolerance/mm.

The radial dimension formula of the cavity is as follows,

$$
M_{S}=(1+S) A_{S}-\left(\Delta+\delta_{Z}+\delta_{C}\right) / 2
$$

(2) The cavity depth dimension is taken as $\delta_{z}=\Delta / 3$. By analogy with the formula of cavity radial dimension, the calculation formula of cavity depth dimension 
is obtained.

$$
H_{M}^{+\delta_{Z}}=\left[(1+S) H_{S}-\frac{2}{3} \Delta\right]^{+\delta},
$$

Calculation formula of radial dimension of core is given by,

$$
B_{M-\delta_{Z}}=\left[(1+S) B_{S}+\mathrm{x} \Delta\right]_{-\delta_{z}},
$$

Core height dimension formula is given by,

$$
\mathrm{h}_{M-\delta_{Z}}=\left[\left((1+S) \mathrm{h}_{\mathrm{s}}\right)+\frac{2}{3} \Delta\right]_{-\delta_{z}},
$$

According to the above formula, the radial and axial dimensions of the cavity plastic parts are $1115.42 \mathrm{~mm}$ and $462.21 \mathrm{~mm}$ respectively, and the radial and axial dimensions of the core plastic parts are $1115.62 \mathrm{~mm}$ and $457.06 \mathrm{~mm}$ respectively. The radial and axial dimensions of the core plastic parts are $1115.62 \mathrm{~mm}$ and $457.06 \mathrm{~mm}$, respectively. The working radial and axial dimensions of the cavity are $1126.57 \mathrm{~mm}$ and $468.85 \mathrm{~mm}$, respectively. The working radial and axial dimensions of the core are $1126.77 \mathrm{~mm}$ and $461.63 \mathrm{~mm}$, respectively. This article uses the UG injection module to model the core and cavity of the outer panel of the plastic rear door of the automobile. The core and cavity are shown in Figure 6.

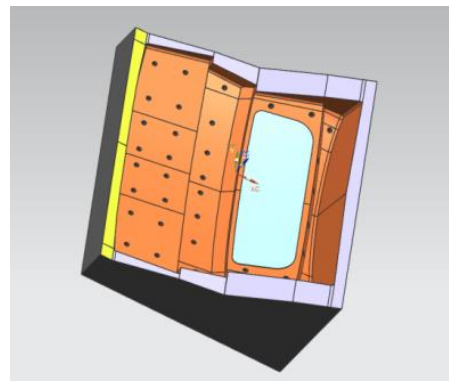

a) Cavity

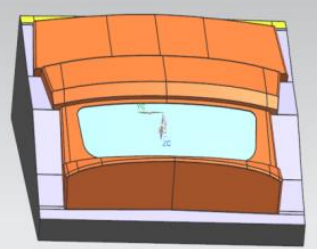

b) Core

FIGURE 6: Core and cavity of injection mold for auto plastic back door plate.

2.2. Mold Assembly Drawing. Before injection molding, the movable and fixed molds are driven by the injection molding machine to complete the closing. The injection molding machine injects the molten plastic in the barrel into the cavity under pressure, and finally obtains the plastic part after a series of molding processes. The mold diagram of the outer plate of the plastic rear door of the automobile is shown in Figure 7. 


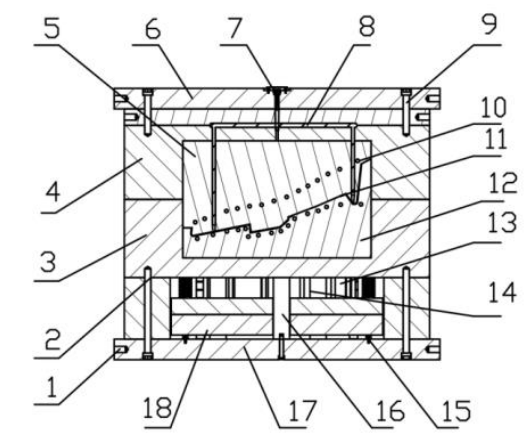

FIGURE 7: Mold assembly section view.

1: bolt; 2: packing plate; 3: B plate; 4: A plate; 5: core; 6: fixed plate; 7: sprue sleeve; 8: gating system; 9: connecting bolt; 10: cooling pipe; 11: parts; 12: mold cavity; 13: moving mold bottom plate; 14: reset rod; 15: garbage nail; 16: ejector rod; 17: fixed plate; 18: roof.

\section{Research on The Gating System and Cooling System of The Outer Panel of The Automobile All-Plastic Rear Door}

The main content of the research on the pouring system and cooling system of the outer panel of the automobile all-plastic rear door is the design and selection of the two major systems of the pouring system and the cooling system during the cooling process. This article determines the pouring location, gate size and cooling system related data, uses Moldflow to analyze, select and verify the designed pouring and cooling system, and determine the best pouring and cooling system.

3.1. Scheme Design of Pouring Position. This article uses Moldflow analysis to obtain a cloud map of gate matching. With the help of actual production experience, this article uses Moldflow gate analysis as an aid to design the gate location and gate quantity. Considering that the plastic back door panel is a large automobile cover, the number of gates is 4, 6 and 8 respectively by the experience of actual production. This article simulates and analyzes the three gate positions, and the results are shown in Figure 8. 


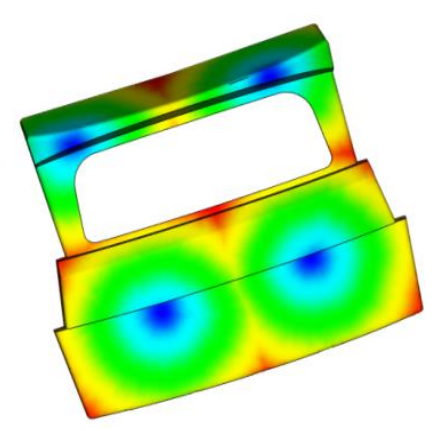

a) Four gate location

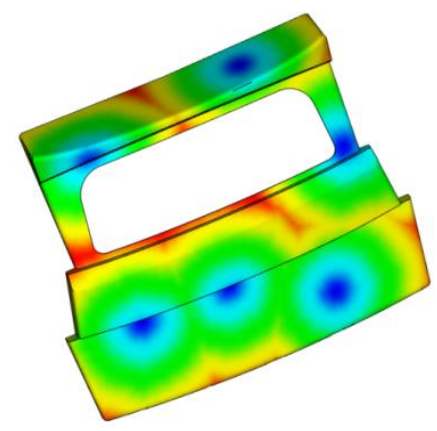

b) Six gate locations

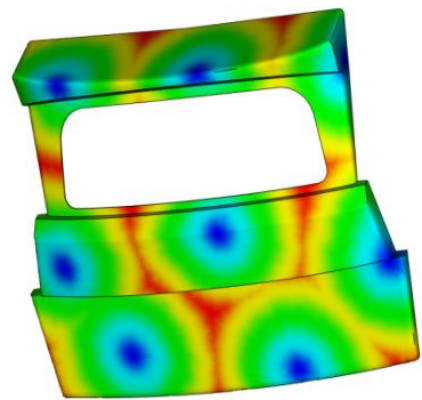

c) Eight gate locations

FiguRE 8: Schematic diagram of flow resistance for different number of gate locations.

It can be judged from the above three figures that the blue area in the figure is the place where the flow resistance is the least, so the blue part is the best gate position simulated by the software. In this paper, Moldflow is used to simulate the filling and flow state of molten plastic in the mold. The injection molding process includes pressure, time and temperature, which needs to be simulated in this paper. The filling time of the eight gates, the temperature difference and the number of weld marks are relatively high among the three schemes, so the scheme of eight gates is excluded first. Compared with the two schemes of four gates and six gates, the difference between filling time and temperature is not significant, but the schemes of fusion connection and die locking force are relatively larger. Considering the actual production situation, the automobile plastic back door panel is a large automobile panel, and it is difficult to achieve the molding effect if there are few gates. Therefore, the scheme with more gates should be selected as far as possible in the case of little difference. Through the above analysis and comparison, this paper finally chooses the pouring plan of six pouring ports.

3.2. Mainstream Design. The main channel is the plastic channel established between 
the nozzle of the injection molding machine and the runner. There are two general design schemes, as shown in Figure 9. Because the ejection position of the plastic rear door of the automobile is in the center of the mold, the main channel of this article chooses the vertical solution.

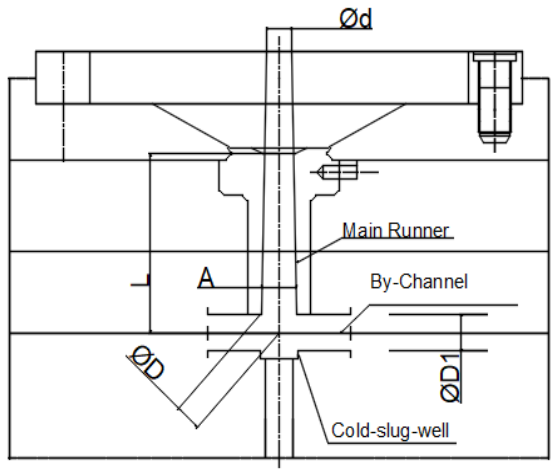

a)Vertical

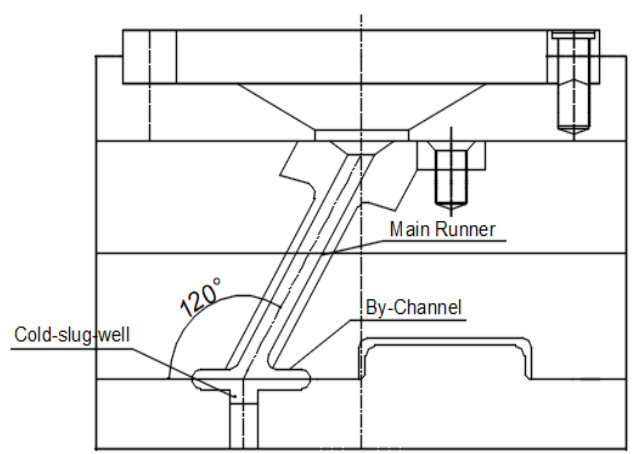

b) Inclined

Figure 9: Mainstream Road Design Scheme.

From the perspective of pressure transmission, the runner requires a larger runner. Compared with other types of cross sections, the circular cross section is the most ideal, and it is also used more frequently. Therefore, a circular cross-section shunt design scheme is chosen in the structural design of the shunt.

3.3. Cold Material Well (Cavity) Design. The cold material well (cavity) is designed to prevent the cold material generated during the injection molding process from entering the cavity, thereby causing damage to the molded part. Cold slug wells are generally distributed at the end of the flow channel, and their location is often at the turning point of the melt flow. The cold material well (cavity) design is shown in Figure 10 . 


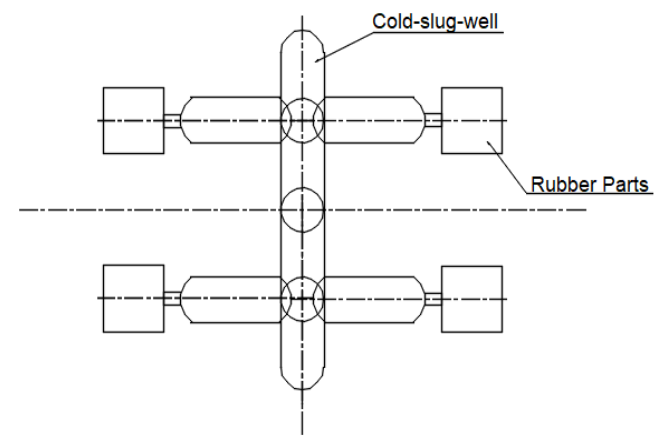

(1)

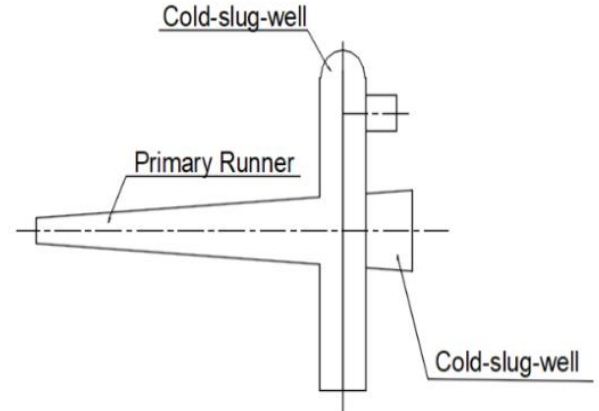

(2)

FIGURE 10: Location of cold material well.

The size of the cold slug well is usually 1.5 to 2 times the diameter of the runner. According to the actual production experience, the length of the cold slug well of the main runner is $27 \mathrm{~mm}$, and the length of the cold slug well of the branch runner is 17 $\mathrm{mm}$.

3.4. The Gate Design. For large plastic parts such as the outer panel of the plastic rear door of an automobile, multiple point gates are usually provided to reduce warping deformation. The schematic diagram of point pouring is shown in Figure 11.

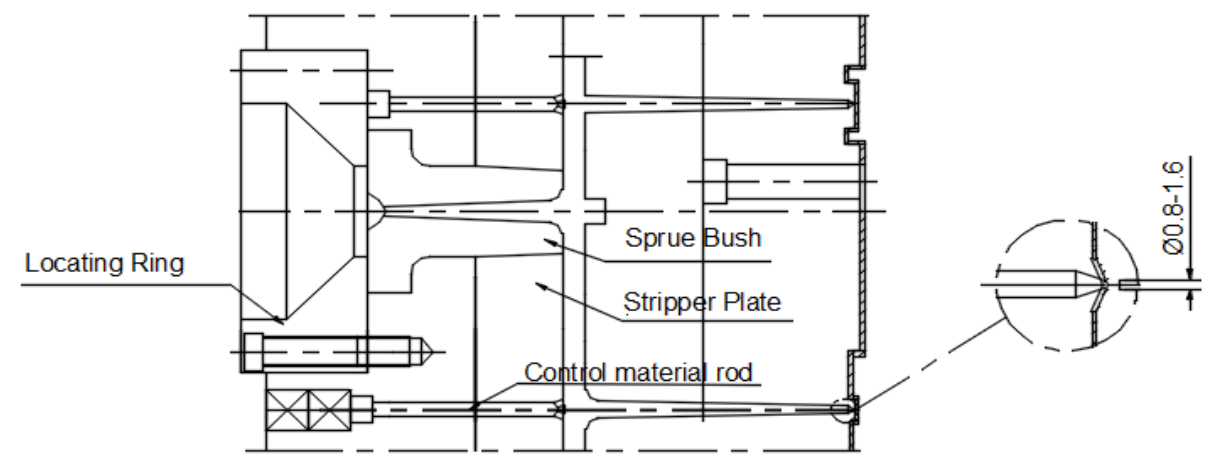

FIGURE 11: Diagram of point gate.

\subsection{Research on Cooling System of Injection Mold for Outer Plate.}

The straight-through type is suitable for the water transportation of the template and the cooling of large plastic parts. The straight-through cooling water circuit is used for the large plastic parts such as the outer panel of the plastic rear door of the automobile. The straight-through cooling water circuit is shown in Fig. 12. 


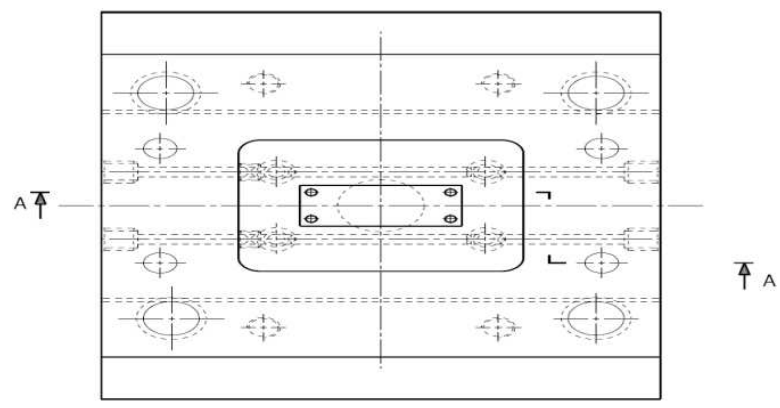

FIGURE 12: Straight cooling waterway.

In mold design, injection molds with relatively high number of cores are often encountered. In this case, cooling water channels with water column channels are required. The water column cooling channel is shown in Fig. 13.

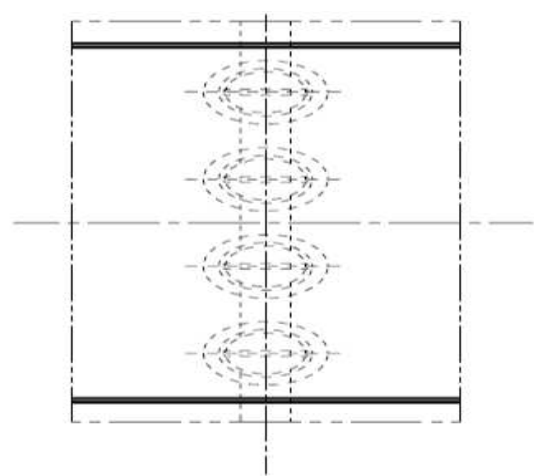

(1)

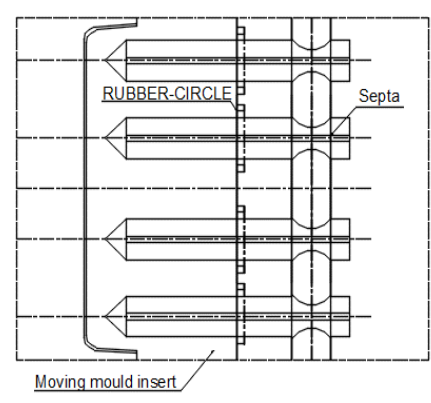

(2)

FiguRE 13: Water column cooling channel.

3.6. Layout of cooling pipes. Taking into account the large size of the outer panel of the plastic rear door of the automobile, the number of cooling pipes should be set as many as possible while ensuring reasonable and no waste. This paper uses this as the premise to design the water circuit. As shown in Figure 14, Moldflow is used to verify the design scheme after the completion of the scheme design. This paper evaluates the temperature, time and other related physical quantities of the waterway layout plan to judge whether the plan is reasonable.
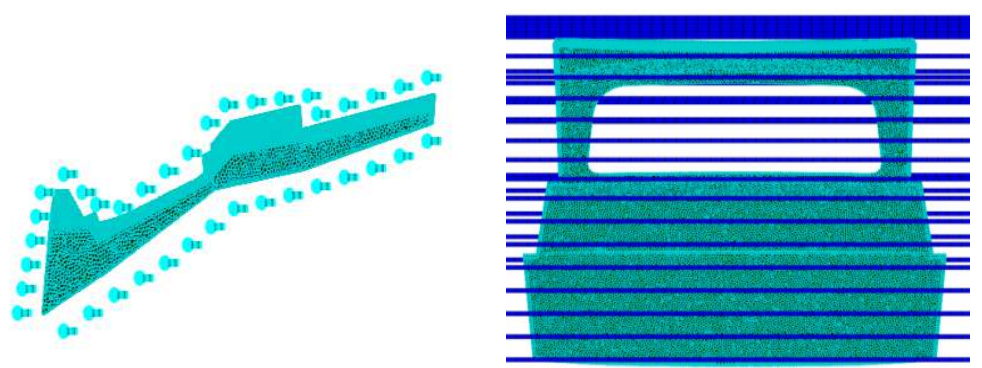
FiguRe 14: Cooling water pipe scheme.

In this paper, the process parameters are set in Moldflow to analyze the cooling process. The time to reach the ejection temperature is shown in Figure 15. Through the analysis of the simulation results, this paper finally chooses this scheme as the cooling water circuit layout scheme.
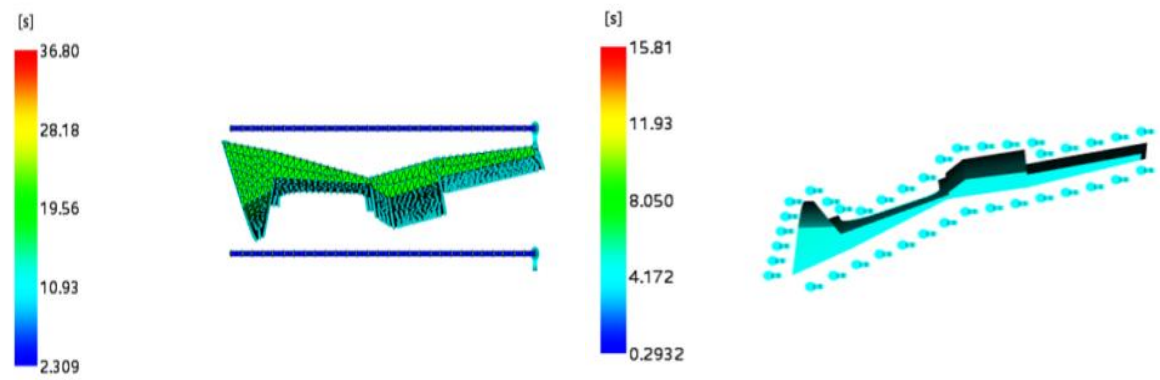

Figure 15: Time taken to reach ejection temperature.

\section{Conclusion}

In this paper, numerical FEM analysis of the plastic rear door outer panel of a certain car is performed. ANSYS and modal analysis software is used to verify whether the designed part can meet its mechanical performance requirements and related mold design issues. According to the structure, material, applications and mechanical properties of the parts, the model HTF300J / TJ of the injection molding machine is selected. According to the principle of parting surface design, UG injection mold tools are used to select the parting surface. The parting surface is formed by expanding the transition area between the inside and outside of the part. The parting surface selected after verification is conducive to the parting. This article draws the general assembly drawing of the mold through the aforementioned design.

In this paper, with the help of Moldflow, different filling and cooling in the injection molding processes are analyzed and studied, and the optimum pouring and cooling system is determined on this basis. This paper uses Moldflow to conduct a simulation study on a six-gate gating system. By comparing each evaluation index, the number of gates selected is 6 . When designing the gate model; point gate with 1.2 $\mathrm{mm}$ diameter, main channel of $18 \mathrm{~mm}$ diameter, and shunt channel of $11 \mathrm{~mm}$ diameter are selected. A cold slug well is also designed similarly. The depth of the cold slug 
well in the main runner is $27 \mathrm{~mm}$, and the depth of the cold slug well in the branch runner is $17 \mathrm{~mm}$. In this paper, the straight-through cooling water channel with diameter of $30 \mathrm{~mm}$ is selected through calculation.

\section{References}

[1]W. Weixing, S.Changhai, S.Haiquan, “Analysis of Development and Application of Full Plastic Back Door for Automobile,”Automotive Technologist, vol.2,2018

[2]W. Zhenjiang, H.Zao, L.Guangyi, et al, “Topology Optimization of Automotive Plastic Bumper Based on Modal Analysis ,"Plastic,vol.5,2017

[3]W. Qian, C.Xiaoyong, "Visualization Analysis of the Research Status of Injection Mold Design in China," Application of Engineering Plastics,vol. 5, 2019

[4] Z. Lei, "Research and Practice of Mold Development Competitiveness," Mold and Die Industry,vol. 4, 2020

[5]Soon Hwan Hwang, Jong sun Kim, “ Injection mold design of reverse engineering using injection molding analysis and machine learning,"Korean Society of Mechanical Engineers, vol. 33, pp. 15-18, 2017

[6]W. Tao, "Lightweight Design Analysis of Automobile B-pillar Based on Manufacturability," Mechanical and Electrical Engineering,vol. 37, pp. 277-282, 2020

[7]S. Maharaja, D. Ravindran, S. Rajakarunakaran, "Effect of Heat Treatment on Formability of AA6082 by Single Point Incremental Forming," Springer Singapore, vol. 33, pp. 11-24, 2019

[8]G.Yuanxi, D.Wuqing, W. Ying, et al, "Optimal Design of Injection Mold for Biological Instrument Cover Plate Based on Moldflow," The Plastics Industry, vol. 47, pp. 64-68, 2019

[9]D. Yu, Study on the Forming Process and Performance of Carbon Fiber Composites for Automotive Inner Plate and Anti-collision Beam, Journal of Donghua University, Shanghai, China,2019.

[10]H. Wenshun, Low Speed Crash Performance Analysis and Optimization Design of Automobile Front Anti-collision Beam, Journal of South China University of 
Technology, Guangzhou, China,2019.

[11]G.Hengya, H. Ming, L. Xin, “Injection molding process analysis and optimization based on CAE technology and product trial production,"The Plastics Industry,vol. 48, pp. 88-91, 2020

[12]W. Yong,Optimal Design of Injection Mold for Automotive Sunlight Based on CAE Warpage Analysis, Journal of Hunan University of Technology, Changsha, China,2017.

[13]L.Bingqiang, Research on Injection Molding Analysis and Clearance Control of Joint Bearings Based on Moldflow, Journal of Yanshan University, Qinhuangdao, China,2019.

[14]D.Yibo, C. Pan, G.Yuhang, "Design of Injection Mould for Fixed Phone Undercover,"Mechanical and Electrical Engineering Technology,vol. 49, pp. $144-146,2020$

[15]Luo Yun-Mei, Luc Chevalier, EricMonteiro, etc, "Simulation of the Injection Stretch Blow Molding Process: An Anisotropic Visco-Hyperelastic Model for Polyethylene Terephthalate Behavior,"Polymer Engineering and Science,vol. 60, pp. $15-20,2020$

[16]Tamaki Y,"Research into achieving a lightweight vehicle body utilizing structure optimizing analysis: aim for a lightweight and high and rigid vehicle body," JSAE Review, vol. 20, pp. 558-561, 1999

[17]C.Yanchun, X.Xuanbo, “Application of Vacuum Brazing Technology in Mold CoolingSystem,"Mechanical and Electrical Engineering Technology, vol. 46, pp. $7-11,2017$ 